\title{
En el desierto, preparar un camino al Señor
}

\author{
José Ignacio González Faus \\ Cristianisme i Justícia \\ Barcelona
}

\section{Introducción: un recuerdo personal}

Como estas líneas tienen algo de homenaje y de celebración, permítaseme comenzarlas con un par de recuerdos personales.

Aterricé en El Salvador por primera vez en agosto de 1980, pocos meses después del asesinato de Mons. Romero. Cuando me recogió Jon Sobrino en el aeropuerto, me contó que se había encontrado allí con no sé qué amiga que le preguntó si se marchaba del país. "Pues no, he venido más bien a recoger a otro hermano", fue la respuesta de Jon, que provocó un comentario asombrado: "Pero ¿están ustedes locos?".

No entendí bien la anécdota sino hasta dos o tres días después, cuando asistí a una reunión de todos los jesuitas de El Salvador, convocada por el provincial César Jerez. Supe entonces que el partido en el gobierno había lanzado una amenaza contra la Orden: "o se van de El Salvador o los matamos a todos". El provincial explicó que una decisión así no podía tomarla él solo y, por eso, había convocado aquella asamblea; que respondieran los presentes y que, por supuesto, quienes desearan salir del país tendrían todas las facilidades para ello. Pues bien, ni uno solo decidió marcharse, el sí a permanecer allí fue unánime. Y quizá convenga aclarar que no todos los asistentes a aquella reunión comulgaban con las ideas y las posiciones de Ignacio Ellacuría y la gente de la UCA. Por mi cabeza sobrevoló rápidamente ("como una paloma") la idea de que una unanimidad como aquella solo podía ser obra del Espíritu Santo.

Si no me falla la memoria, fue en aquella primera estancia cuando oí a Ellacuría hablar con los de la UCA sobre el proyecto de una revista latinoamericana de teología: posibilidades de difusión, de financiación, si había otra 
publicación así en América Latina... Al final, se optó por que fuera cuatrimestral y no trimestral, por razones de prudencia económica. Otra vez pensé que el asesinato de Mons. Romero, en lugar de acallar a mis hermanos, iba a darles más voz. Y fue más o menos por entonces cuando me dije que la teología no era más que una forma de poner en práctica la recomendación del profeta Isaías y del evangelista Marcos: "en el desierto, preparar un camino al Señor".

Por eso, he querido comenzar con este recuerdo personal. En el desierto salvadoreño, en este desierto mundial, poco a poco, de manera casi artesanal, pero ininterrumpida -aunque en 1989 fueran asesinados Ellacuría y sus compañeros-, los cien números de la Revista Latinoamericana de Teología han intentado abrir ese camino, que consiste en "hacer llanas las sendas del Señor" (Mc 1,5): rebajar lo que está muy alto y elevar lo que está muy hundido.

Cuando ahora vuelvo la vista atrás, se me asocian estos dos temas: la visión de la teología como humilde preparación del camino para el Señor y la experiencia del Espíritu Santo, que hoy se busca bajo el término de espiritualidad. He escrito repetidas veces - sin ser el único en esa constatación- que la teología occidental adolece de una llamativa falta de atención al Espíritu y que esa laguna se deja sentir hoy bastantel. Voces más críticas podrán atribuir esa ausencia al juridicismo romano o al intelectualismo griego, a una pretensión de "acaparar al Espíritu" por parte de la curia romana, no dejándole soplar donde quiere, o a un espiritualismo que no permite al Espíritu posarse en la carne del Hijo, que habría sido el fallo de tantos movimientos pentecostalistas postconciliares. Pero, más que un momento de críticas, me parece ser esta la hora de una seria reflexión pneumatológica. Quisiera decir en este apunte que la teología de la liberación está urgentemente llamada hoy a ser una "pneumatología de la liberación". De hecho, ya en sus comienzos alertó Gustavo Gutiérrez de que la teología de la liberación era una forma de teología espiritual. Aunque entonces eso solo sirviera para que la desacreditaran algunos "logomaníacos" europeos.

Tras esta introducción, intentaré orientar mis prismáticos hacia el futuro, para ver si es posible atisbar algo de esa pneumatología de la liberación.

\section{2. "Donde está el Espíritu de Dios, ahí hay liberación"}

Más allá de las críticas antes aludidas, una de las razones que hacen comprensible la pobreza de nuestra pneumatología es que el Espíritu no puede tener palabra, aunque vaya siempre unido a esta. Urs von Balthasar decía que el Espíritu está "más allá del Logos" y algún santo padre intentaba explicar algo de eso, afirmando que el Espíritu no es la palabra, sino "la voz" que pronuncia esa palabra.

1. Remito al último capítulo de Herejías del catolicismo actual (Madrid: Trotta, 2013). 
Esta dificultad me ha llevado a pensar que quizás una buena pneumatología habría de tener el valor de hablar del Espíritu como "lo impersonal" de Dios, aunque esto suene a herético porque, para nosotros, lo impersonal resulta siempre menos perfecto que lo personal y en Dios no cabe la imperfección. Pero ya los mejores tratadistas de la Trinidad $-K$. Rahner, entre ellos - han insistido en que el término persona se aplica al Espíritu en un sentido "muy analógico", no solo respecto a lo que ese término significa en nosotros, sino respecto a lo que significa cuando lo aplicamos a las personas de la Trinidad. Y además, sabemos que todo lenguaje sobre Dios no puede ser en absoluto cartesiano, sino dialéctico: san Agustín lo vivió como profundamente inmanente y profundamente trascendente; hablamos de Él desde el ser y "sin el ser"2, como interior y exterior, como justo y misericordioso...

De hecho, muchos calificativos que el Nuevo Testamento aplica al Espíritu son de carácter impersonal. Quizá, pues, valga la pena detenernos un poco en algunos.

El Espíritu es la fuerza de Dios, de tal modo que Jesús muere entregándose "por [la fuerza d]el Espíritu" (Heb 9,14). Cuando el Espíritu desciende sobre María, la cubre "la Fuerza del Altísimo" (Lc 1,35). Más tarde, Jesús inaugurará su ministerio regresando del desierto a Galilea, "por la fuerza del Espíritu Santo" (Lc 4,14); y los apóstoles comenzarán a predicar "con audacia, llenos del Espíritu" (Hch 4,31) ${ }^{3}$. Todas las imágenes bíblicas del soplo y del viento encarnan esa idea de la fuerza.

No creo exagerado afirmar que la teología de la liberación nació por esa fuerza del Espíritu de Dios, que sopla donde quiere. Y que, gracias a la fuerza de ese viento, la teología de la liberación atravesó el desierto para regresar al terreno de la predicación de Jesús: a "Galilea". Lo hizo superando no solo lo "carnal" y el pecado de algunos de sus protagonistas (que también), sino, además, las críticas y desautorizaciones de "sumos sacerdotes y potentados" (Mt 21,23), que pretendían juzgarla, preguntando con qué autoridad actuaba así. Cerremos, pues, esta reflexión como Pablo cerraba su carta a los romanos: que el Dios de la esperanza los colme de paz y de gozo en su fe, para que crezca cada vez más su esperanza por la fuerza (en dynamei) del Espíritu Santo $(15,13)$.

El Espíritu Resplandor de Dios. Con lenguaje bíblico, el Espíritu es Luz y vista. Ambas palabras han perdido fuerza para nosotros, porque ya no tenemos la experiencia de lo que significaban la oscuridad y la pérdida de visión, en unas épocas en las que no existía la electricidad, ni las gafas. No podemos objetivar nuestros propios ojos para verlos y hablar de ellos -y si los objetivamos en un

2. Así, J. L. Marion, Dieu sans l'être (París: Puf, 2013).

3. La audacia en el hablar, esa parresia tan típica del Nuevo Testamento, aparece por primera vez como fruto de la presencia del Espíritu. 
espejo, no los veremos tal cual son, sino invertidos. Pero vemos con esos mismos ojos a los que no podemos ver. De ahí la dificultad de hablar sobre el Espíritu, como no sea describiendo sus efectos en nosotros: solo con esa Luz del Espíritu podemos llamar señores a los pobres e invocar a Dios como "Dios de los pobres" y como Abbá de todas las víctimas de esta historia.

Pues bien, eso es exactamente lo que ha querido hacer la teología de la liberación; y creo que, desde esta óptica pneumatológica, se comprende la discutida designación de la teología como "acto segundo", propia también de G. Gutiérrez. Por eso, como Jesús, ha podido dar la misma señal de su misión que dio el Maestro: hay esperanza para los privados de ella y hay una buena noticia para los pobres (cfr. Mt 11,2ss).

El Espíritu es la máxima interioridad de cada ser humano: si somos capaces de amar con un amor como el de Dios y con esperanza, es "por la inhabitación del Espíritu en nosotros (Rom 5,5). Es así como el "dulce huésped del alma" se convierte a la vez en "dulce refrigerio" y en "padre de los pobres". $\mathrm{Y}$ es dato conocido que en el Nuevo Testamento hay pasajes en los cuales no queda claro si el Pneuma designa al Espíritu Santo o al espíritu humano.

Etty Hillesum encontró a Dios en esa experiencia de lo mejor de la propia intimidad. Sorprende la seguridad con que escribe en su diario: "dentro de mí hay un pozo muy profundo y ahí dentro está Dios. Pero a menudo hay piedras y escombros taponando ese pozo y entonces Dios está enterrado. Hay que desenterrarlo de nuevo"s. A partir de entonces, rezará: "tu hogar, Señor, es mi interior". Encontrará a Dios en esa profundidad propia purificada; y este hallazgo no le impide - al revés, le posibilita - encontrar a Dios fuera de ella. De modo que ese "continuo escucharme a mí misma" se le convierte en "un escuchar a los demás y a Dios" (17 de septiembre de 1942).

De aquí brotan tres observaciones importantes: (a) una cristología del Espíritu, que hoy tanto se ha reclamado con razón y que podría orientarnos más a la intimidad de Jesús, no puede darse al margen ni en contra de una cristología del Logos. Al contrario, es lo que la hace posible: "la relación íntima entre la actividad del Espíritu y el misterio del Hijo en vistas a su realización en el mundo, se impone a la teología como un hecho de importancia capital"6. (b) En segundo lugar, esta pneumatología abre otra vez el camino al encuentro con místicas no cristianas: el hinduismo, por ejemplo. Pero sabiendo que no se trata

4. Expresiones todas de la célebre secuencia de la misa de Pentecostés.

5. Día 26 de agosto de 1941. El título del diario es Una vida conmocionada (Barcelona: Anthropos, 2007).

6. F. J. Durrwell, El Espíritu Santo en la Iglesia, p. 36 (Salamanca: Sígueme, 1983). Subrayado mío. Eso es lo que quizá no supo ver la cristología de R. Haight (Jesús símbolo de Dios) tan valiosa, por otra parte. 
de una afirmación genérica de la propia interioridad divina, sino que es necesario bajar concretamente hasta ella. Allí es donde se percibe que el encuentro con Dios en la propia intimidad -o, dicho cristianamente, la experiencia del Espíritu - nunca termina en un quedarse allá dentro, sino en un "salir" hacia fuera; porque, como escribe muy bien Durrwell, "el que es el misterio íntimo es también la propensión de Dios a salir de sí mismo. El Indecible lleva a Dios a decirse en su Palabra, en el Mesías [esto es, en la historia] y en la creación"7. Esta es, en mi opinión, la irrenunciable aportación bíblica a las religiones del oriente.

Y (c) La teología de la liberación puede parodiar así la célebre estrofa inicial de Juan de la Cruz: en una tierra oscura, con ansias en amores inflamada, ha tenido la dichosa ventura de salir hacia fuera de sí. Pero sale "estando ya mi casa sosegada". Esa ventura dichosa se expresó en aquello de que "los pobres nos evangelizan". Pero requiere ese sosiego del propio ego, para poder ser paladeada.

El Espíritu es amor. Para Pablo, caminar en el Espíritu y caminar en el amor es lo mismo (Rom 8,4.5). Precisando más, el Espíritu es la apertura del amor o, como diría Ricardo de san Víctor, la prueba de que el amor no es exclusivista y cerrado sobre sí mismo. Es por eso muy significativo que Ricardo arranque su reflexión sobre la Trinidad no de un análisis abstracto del amor, sino de aquellos pasajes concretos de los Hechos de los Apóstoles, donde se habla del "comunismo" de la Iglesia primera (Hch 2,44-47 y 4,32-36); y que vincule esa reflexión trinitaria con la idea del hombre como "imagen de Dios". Ambas cosas son decisivas para una teología de la liberación y conviene mirarlas un poco más.

$\mathrm{El}$ amor es lo que da valor a las personas: el hombre solo es verdaderamente hombre en el encuentro interpersonal ${ }^{8}$. Ello se debe a que Dios solo es el Dios verdadero en la comunión absoluta ${ }^{9}$. Si la experiencia del acontecimiento de Jesucristo concluyó en la afirmación de que "Dios es Amor" (1 Jn 4,20), la reflexión sobre la Trinidad será una reflexión sobre el amor elevado al infinito. El Padre será así el amor que sale de sí mismo y, en ese salir, es persona; el Hijo será el amor recibido que, en ese recibir, cuaja como persona; y el Espíritu será el encuentro de ambos en una mirada hacia fuera, por la que esa unión absoluta no se cierra en sí, sino que se vuelve fecunda y culmina en lo que Ricardo llama un "condilecto" 10 . Aunque habría que subrayar un poco más que ese condilecto es

7. Ibid., p. 40.

8. Como enseñará más tarde el personalismo de Mounier. De ahí su talante tan cercano con la teología de la liberación.

9. Ricardo se aparta así del enfoque individualista agustiniano, que ha marcado mucho más a occidente, y que acabó convirtiendo el tema de la Trinidad en una verdad inútil (Kant) o en una especulación de matemáticas irracionales.

10. Antaño se hizo famosa la frase hoy olvidada, que creo es de Saint Exupéry: "amor no es mirarse el uno al otro; es mirar juntos en la misma dirección". 
el que mantiene inseparablemente unidos al Padre y su Palabra, culminando así, valga la expresión, el ser-persona de entrambos.

Dios es, pues, donación, comunión y codilección. Habrá que añadir que, aplicadas a Dios, todas estas reflexiones tienen "más desemejanza que semejanza", tal como enseñó el Lateranense IV de todo lenguaje sobre Dios. Pero su valor teológico radica, como el de toda buena teología, en su valor antropológico: de ella brota que la persona humana es, a la vez, sujeto-relación-y-comunión. Y que las diversidades no están para ser suprimidas, ni dominadas, sino para ser respetadas en la comunión igualitaria. Ahí reside la verdadera libertad para la que Cristo nos liberó (Gal 5,1): porque en Dios, amor y libertad se identifican. Mientras que en nosotros, citando otra vez a Durrwell, "sin el amor, la libertad no se reivindica más que a costa de los otros"'!.

La pneumatología de la liberación pone así de relieve la ausencia del Espíritu, en un mundo que se cree humanamente desarrollado y que, aun cuando nació de matriz cristiana, se caracteriza por su absoluta falta de comunión, o de "codilección", con todas las víctimas de esta tierra, generadas en buena parte por él mismo. Algo de esto atisbaba la primera teología de la liberación, al hacerse brotar de la experiencia del éxodo, tras la opresión de Egipto, que así se globalizaba. "Egipto es el mundo", quería decir aquella teología, parodiando, sin saberlo, una frase de Agamben que luego citaremos. Y hoy, esa pneumatología sirve para denunciar que nuestra pretendida "globalización" es solo una forma de tiranía ante la cual el recurso al faraón también resulta inútil, como lo fue antaño.

Por supuesto, se trata solo de denunciar una situación, no a las mil excelentes personas que pueden vivir en ella, sin ser responsables de esa opresión, pero con la amenaza de volverse cómplices de ella. Pero esa denuncia, y la necesidad de salir de tal situación, ponen de relieve que el Dios de occidente, infinidad de veces, no es el $A b b a ́$ anunciado por Jesús, sino el "Predestinador" de Godescalco y de aquellos calvinistas que emigraron a América del Norte, buscando en el propio enriquecimiento la prueba de que Dios estaba de su parte ${ }^{12}$. Pone de relieve que el Cristo de occidente, infinidad de veces, no es el Jesús "hombre para los demás", sino un nimbo de sacralidad, que rodea muchas veces al poder y no a la fraternidad. Por eso, ante el inmenso dolor de este mundo -dolor además injusto en infinidad de ocasiones-, la teología de occidente puede acabar convirtiéndose en lo que G. Gutiérrez calificó como teología "de los amigos de Job".

Digamos, para cerrar esta larga reflexión, que, como Jesús, la teología de la liberación "puso en evidencia los corazones de muchos" (Lc 2,34), y esta fue

11. F. J. Durrwell, El Espíritu Santo en la Iglesia, o. c., p. 186.

12. Aludo solo genéricamente a la tesis de Max Weber, sin entrar en la discusión posterior de si aquella teología era verdaderamente de Calvino. En todo caso, sí creo que esa teología es la que acabó corrompiendo el precioso "sueño americano" inicial. 
la razón por la que, como a Jesús, se intentó condenarla con el más negativo de los sambenitos del momento. Pero, a pesar de eso, la pneumatología de la liberación pone de relieve que si aceptamos ese "amor de Dios derramado en nuestros corazones por el Espíritu", estamos sostenidos por "una esperanza que no defrauda", aun cuando ese amor tenga que actuar en medio del cautiverio o de la persecución.

Por todo lo anterior, el Espíritu es además la gloria y santidad de Dios. Gregorio de Nisa explicaba que la promesa de Jesús - "les daré la gloria que Tú me has dado"-, la cumplió cuando dijo: "reciban el Espíritu Santo"13.

Pero la gloria es una palabra muy imprecisa, porque, entre nosotros, alude a algo que "se recibe" desde fuera. Y Dios no necesita que le demos ninguna gloria, ni se la damos simplemente diciendo "gloria al Padre y al Hijo...", etc. Los cielos "narran" esa gloria de Dios (Sal 19), pero no se la tributan. Y es que la gloria de Dios es el mismo resplandor de su ser, que llena el universo. Por eso, la Biblia la identifica prácticamente con la Santidad de Dios, la mejor palabra que se encontró para señalar el resplandor de la trascendencia divina - "solo Tú eres Santo [...] llena está la tierra de Tu gloria"14 —, porque no alude a una trascendencia meramente ontológica, sino que destaca el ámbito del amor, de la bondad, de la misericordia o de la justicia.

Esa "gloria de su poder nos fortalece para ser pacientes y magnánimos con gozo" (Col 1,11), porque la contemplamos, precisamente, en el "hacerse carne" de la Palabra (Jn 1,14). Por eso, somos "santificados por el Espíritu"15, y por eso, el juicio de Dios tiene lugar "ante la gloria de su fuerza" (2 Tes 1,9). Por eso también, se pudo decir, desde los inicios del cristianismo, que "la gloria de Dios es que el hombre viva"16.

Por dar a Dios esa gloria verdadera, la teología de la liberación ha devuelto credibilidad al cristianismo y ha puesto de relieve los corazones de muchos.

Paradójicamente, y por lo incomprensible de Dios, es el lenguaje impersonal el que más nos acerca a la personalidad del Espíritu. Él es también consolador y abogado defensor, mostrándonos así que, en el misterio infinito de Dios, lo impersonal no es accidente, ni imperfección, sino que es la suprapersonalidad misma de Dios. Es esa fuerza del amor y esa luz de la propia intimidad, y el resplandor de ambas, lo que convierte al Espíritu en el "otro Paráclito" prometido

13. PG 44, 1117. Es de una de sus homilías sobre el Cantar de los cantares.

14. Cfr. Is 6,3 .

15. Rom 15,$16 ; 1$ Cor 6,$11 ; 1$ Pe $1,2 \ldots$

16. Es sabido que esa expresión (gloria Dei vivens homo) proviene de san Ireneo (del siglo II) y que Mons. Romero, en su discurso de Lovaina, la parafraseó como gloria Dei vivens pauper. 
por Jesús. Y lo que convierte el "ven, Espíritu Santo" en la plegaria más propia del cristiano.

La misión de Consolador puede además dar pie a la concepción del Espíritu como "lo femenino de Dios", tal como está representado en la célebre imagen de la Trinidad en la iglesia de Urschalling (Alemania), con casi mil años de existencia. Sin hacer apropiaciones exclusivas, pero sí representativas, eso serviría para reclamar una dimensión más femenina en la teología de la liberación, que atendiera tanto al cambio imprescindible de las estructuras como al cuidado personal ${ }^{17}$ : porque este devuelve a las víctimas y a los excluidos el sentimiento de dignidad, imprescindible y muy consolador, y que brotaba sencilla y constantemente de las homilías de Mons. Romero ${ }^{18}$. Déjeseme concretar esto con un ejemplo vivido hace poco, aquí en Barcelona.

Un grupo de gente dedicada al teatro estuvo durante una temporada en diversos lugares de Grecia, escuchando a refugiados llegados de Siria, Irak, etc. Con esos relatos, compusieron una pieza que fue leída en el Teatro Nacional de Barcelona, el pasado diciembre. Prescindiendo ahora de la buena calidad de la pieza y de la representación, el dato que quiero destacar es que fue retransmitida por streaming, de manera que sus protagonistas pudieron seguirla desde los lugares donde están ahora. Y, aunque entenderían muy poco por estar hablada en catalán, el mero hecho de que su tragedia mereciera aquella atención, aquel interés y aquella publicidad, les llegó tan adentro, que no solo aguantaron las casi dos horas de representación, sino que, nada más concluir esta, comenzaron a enviar whatsapps de gratitud a los actores. El reconocimiento de su dolor les devolvió la conciencia y la dignidad de personas.

En conclusión, no parecerá exagerado si concluimos parodiando a san Pablo: donde esté el Espíritu de Dios, allí habrá una teología de la liberación ( $c f r .2$ Cor 3,17). Aclarando, como antaño lo hiciera Hugo Assmann, que al hablar de liberación en vez de libertad, se destaca el carácter dinámico y nunca plenamente conseguido de esa libertad. Lo cual nos lleva al capítulo siguiente.

\section{Preparar el camino al Señor}

Si el apartado anterior ha pretendido actuar como "acicate escatológico", expresión del inolvidable J. Jiménez Limón, en este habrá que recurrir al tan

17. Leonard Ragaz hablaba, ya a comienzos del siglo pasado, de la misión del médico y la de la enfermera. Esta es absolutamente imprescindible, aunque sea insuficiente. Y aquella resulta poco humana sin esta. Y, otra vez, no se trata de tomar ambos términos como definiciones, sino solo como representaciones.

18. Ya en 1980, en un soneto dedicado a la muerte de Mons. Romero, hablé de "devolver al pobre la primicia de dignidad ganada al escucharte". 
europeo "reparo escatológico". Así, nos mantendremos en esa fórmula clásica de la teología: "ya sí, pero todavía no".

La teología debe intentar humildemente preparar un camino, porque el Espíritu no actúa de manera mágica o milagrosa, sino que posibilita el que hagamos nosotros, así como prepararon ese camino del Señor el "fíat" de María, o el anuncio del Bautista, o los envíos de los discípulos con la doble misión de anunciar y poner signos.

Pero además, ese camino se abre en el desierto: lugar del hambre, la sed y la tentación. Y aplicando esa denominación no a un lugar apartado de nuestro planeta, sino a la situación misma de este mundo. Una tremenda experiencia de ese "desierto" lo fueron, en nuestros días, los campos de concentración nazis. Y G. Agamben se atrevió a escribir después, aludiendo a aquel horror: "el campo es el mundo"'19.

Para simbolizar esa tarea en el desierto, pueden servirnos también las tres metas que se asignaba a sí misma Etty Hillesum en su diario: "ayudar a Dios", convertirse en el "corazón pensante" del campo y tratar de ser un "bálsamo para tantas heridas". Una rápida palabra sobre cada una.

Ayudar a Dios. Desde su experiencia espiritual, Etty no temió hablar así, aunque ese lenguaje pareciera atentar contra la omnipotencia del Dios de los teólogos amigos de Job. Ese lenguaje suponía para ella tratar de que Dios no muera - o no quede "enterrado"- entre los mil escombros que hay en el fondo de nosotros: en los opresores por su inhumanidad y en los oprimidos por su situación de infrahumanidad ${ }^{20}$. Suponía también, dicho ahora con lenguaje teresiano, saber que "Dios no tiene otras manos que las nuestras". $O$, con lenguaje de Vicente de Paúl, comprender que la mejor manera que tenemos para amar al Dios trascendente es amar aquello que Él ama, aquellos a quienes Jesús llamaba, por eso, bienaventurados.

Le segunda expresión la acuñó Etty durante su estancia en el campo de Westerbork (Holanda) como asistenta social. La adoptó como una oración - "permíteme ser el corazón pensante de este barracón"21 — y sirvió para titular el libro, que recoge las cartas escritas desde allí. En aquel lugar, dominado por la necesidad de sobrevivir, de mantas, de alimento..., que absorbía todo el tiempo y todas las energías de la gente, ella se propone "estar presente (...) un poco como

19. Repetidas veces en Homo Sacer.

20. E. Hillesum, Una vida conmocionada, 11 y 12 de julio de 1942, pp. 137-143 (Barcelona: Antrohopos, 2007). Las comenté un poco más en Etty Hillesum: una vida que interpela, pp. 70-73 (Santander: Sal Terrae, 2008).

21. E. Hillesum, o. c., 3 de octubre de 1942, p. 193. 
el alma de este cuerpo"22, procurando que la gente no se empobrezca humanamente. Pero atendiendo también a que el dolor de la propia solidaridad no la ciegue a ella, ni agote su capacidad de razonar, para saber encontrar las mejores soluciones o, al menos, las menos malas.

La genial propuesta de la teología de la liberación, de convertir las ciencias sociales en ayudantes de la teología - como antaño lo fue la filosofía, y sin dejar a esta-, puede encontrar aquí una forma de expresarse. $Y$ a la vez, pone de relieve el fallo de aquellos críticos que, ante el binomio "razón y fe", reducían la primera a una racionalidad fría, abstracta, y no a una cordial.

El bálsamo es una expresión de humildad. La teología de la liberación no pretendió ser salvadora. Pero esto tampoco justifica la pereza, ni esa indiferencia que pasa por ser el mayor pecado de hoy -incluso mayor que la misma opresión. Etty habla en otro momento de "llevar flores y frutos a cada trozo de tierra a donde uno va"23. Esa tarea implicará el contacto directo con la gente, para que la opresión no sea cuestión de cifras y estadísticas abstractas, sino de rostros muy concretos e interpeladores ${ }^{24}$. La llamada "teología del pueblo", que algunos quisieron oponer interesadamente a la teología de la liberación, se convierte aquí en una gran ayuda de esta.

\section{Conclusión}

Sin duda alguna, el cambio estructural, que sería convertir el desierto en tierra fértil, sigue siendo objetivo primario. Al menos, se han instaurado ya expresiones como la de "pecado estructural" o injusticia estructurada (Juan Pablo II). Pero esa es tarea a muy largo plazo. Para posibilitar el trabajo hacia esa meta, es urgente hoy crear un oasis en el desierto. Ojalá la Revista Latinoamericana de Teología siga manteniendo vivo ese acicate, en medio del desierto neoliberal, que tantas veces impide la plenitud.

22. E. Hillesum, o. c., 16 de septiembre de 1942, p. 167.

23. E. Hillesum, o. c., 2 de octubre de 1942, p. 155.

24. "Me gusta tener contacto con la gente", en E. Hillesum, o. c., 4 de octubre de 1942, p. 194. 